\title{
Predicting mortality from cancer of the uterine cervix from 1991-2001
}

\author{
M Murphy, C Osmond
}

\begin{abstract}
Study objective-The aim was to provide benchmarks by which to judge the success of behaviour change and the cervical cancer screening programme in England and Wales in reducing mortality from this disease over the next decade.

Design-Log-linear models and cervical cancer mortality data by age and marital status from 1959-88 were used to predict future mortality in England and Wales.

Measurements and main resultsRecombining "predicted" deaths in marital status groups for 1984-88 gave a closer agreement to total mortality observed in those years than predictions based on past trends from 1959-83 among women of all statuses combined. Mortality for 1989-2003 was then predicted, using the data for 1959 1988.

Conclusions-The reaggregated marital status forecasts of mortality provide an upper boundary which future observed mortality should not cross if primary and secondary prevention measures are working effectively. The method allows swift comparison of observation with expectation and therefore the rapid evaluation of the overall performance of preventive strategies.
\end{abstract}

Opinion varies about the success of the cervical cancer screening programme in Britain, but there is sufficient concern that it is not as effective as it should be for there to have been recent major changes in its organisation and management. ${ }^{12}$ However, there remains the problem of evaluating the programme's efficiency and effectiveness. Various qualitative and quantitative methods have been proposed, with more or less applicability to the local and national situation, and with more or less monitoring potential, ie, the ability to evaluate recent rather than historic performance. ${ }^{3}$ We propose here a further approach to monitoring national performance which predicts the future mortality (or incidence) that would be expected on the basis of trends to date and allows a timely comparison of this expectation with observed mortality (or incidence) in due course.

Any prediction of the burden of cervical cancer must take account of the strong variation in risk of the disease among women born in different generations. A previous prediction of mortality for 1986 among all women in England and Wales, based on age and cohort trends from 1950-83, was found to overestimate the deaths actually observed in that year by $5-6^{\circ}{ }_{0} \cdot{ }^{4}$ However, this analysis did not take into account that cohort and period trends in mortality by age and marital status are known to be very different. ${ }^{5}$ We therefore investigated the effect on predictions of mortality over the longer term among all women, of separately forecasting death rates among the single, married, widowed, and divorced, and recombining them using the government actuary's population projections by marital status to produce a reweighted expected total for all women. 6

\section{Methods}

We fitted a log-linear model containing terms for age, period, and cohort to cervical cancer mortality data for England and Wales obtained from the Office of Population Censuses and Surveys, using five year periods from 1959 to 1983 and five year age groups from 20 to 69 years. We used data below age 70 years because cause of death is more accurately stated there. Although 1950 is the first year for which deaths from cervical cancer are recorded separately from those for other uterine cancers, 1959 is the first year for which cause specific mortality by marital status is readily available. The fitting was done for all women, and for the four separate marital status groups (single, married, widowed, divorced). We used the age-period-cohort model and the agecohort model ${ }^{7}$ to predict mortality for 1984-88. We tested whether recombining the separate marital status projections would give a prediction closer to the observed mortality rates than would the simple projection for all women regardless of marital status. Finally we predicted deaths from 1989-2003 using data from 1959-1988 and the relevant population projections.

\section{Results}

The figure shows the pattern of mortality by marital status over the period 1959-88 when fitting the age distribution for all women and separate cohort effects only for each marital status group. The experience of single women is markedly different from that of women who have been married. The cohort experiences of the latter follow the same general pattern but their absolute mortality rates differ in a relatively fixed relationship until the generation born around the time of the second world war. From around that time onwards, succeeding generations of women experience increasing risk, irrespective of marital status.

Table I shows the results of predicting mortality in 1984-88 using the 1959-83 data in 
both an age-period-cohort model and an agecohort only model, for all women and for recombined marital status groups. With both models the recombined marital status total gives a somewhat lower figure in closer agreement with observed deaths, and the age-cohort model is a
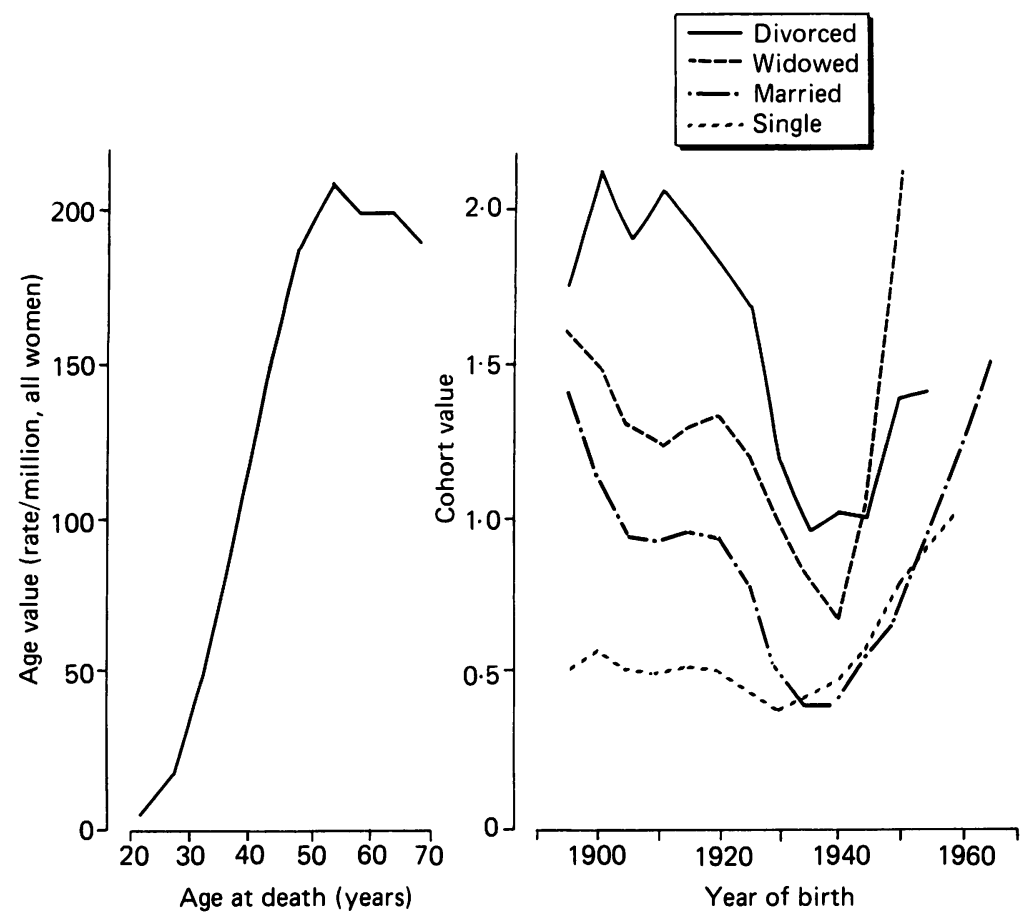

Cervical cancer in England and Wales, 1959-1988, ages 20-69 years. Mortality rates according to age and year of birth

Table I Observed deaths 1984-88 age 20-69 years and numbers of deaths predicted using age-period-cohort and age-cohort models for all women and reaggregated marital status (MS) total

\begin{tabular}{|c|c|c|c|c|c|}
\hline \multirow[b]{2}{*}{$\begin{array}{l}\text { Age } \\
\text { (years) }\end{array}$} & \multirow[b]{2}{*}{$\begin{array}{l}\text { Observed } \\
\text { deaths }\end{array}$} & \multicolumn{2}{|c|}{ Age-period-cohort } & \multicolumn{2}{|c|}{ Age-cohort } \\
\hline & & $\begin{array}{l}\text { All } \\
\text { women }\end{array}$ & $\begin{array}{l}\text { Reaggregated } \\
M S \text { total }\end{array}$ & $\begin{array}{l}\text { All } \\
\text { women }\end{array}$ & $\begin{array}{l}\text { Reaggregated } \\
\text { MS total }\end{array}$ \\
\hline $\begin{array}{l}20-24 \\
25-29 \\
30-34 \\
35-39 \\
40-44 \\
45-49\end{array}$ & $\begin{array}{r}30 \\
196 \\
370 \\
604 \\
613 \\
605\end{array}$ & $\begin{array}{r}56 \\
208 \\
479 \\
815 \\
715 \\
625\end{array}$ & $\begin{array}{r}37 \\
178 \\
470 \\
811 \\
687 \\
620\end{array}$ & $\begin{array}{r}54 \\
201 \\
466 \\
795 \\
704 \\
620\end{array}$ & $\begin{array}{r}37 \\
177 \\
468 \\
781 \\
674 \\
615\end{array}$ \\
\hline All under 50 & 2418 & 2898 & 2803 & 2840 & 2752 \\
\hline $\begin{array}{l}50-54 \\
55-59 \\
60-64 \\
65-69\end{array}$ & $\begin{array}{r}699 \\
857 \\
1241 \\
1240\end{array}$ & $\begin{array}{r}616 \\
782 \\
1267 \\
1293\end{array}$ & $\begin{array}{r}624 \\
799 \\
1268 \\
1296\end{array}$ & $\begin{array}{r}610 \\
779 \\
1266 \\
1303\end{array}$ & $\begin{array}{r}619 \\
798 \\
1271 \\
1306\end{array}$ \\
\hline All under 70 & 6455 & 6856 & 6790 & 6798 & 6746 \\
\hline
\end{tabular}

better predictor, suggesting that inclusion of a period term is unwarranted. This is confirmed by the minor improvements in goodness of fit associated with the inclusion of the period term.

Table II shows the results of predicting average mortality for the five year periods, the mid-years of which are 1991, 1996, and 2001, using all the data from 1959-88 and the relevant population projections, once again using both age-periodcohort and age-cohort models for all women and recombined marital status groups. An increasing proportion of deaths at younger ages is evident in each prediction and the age-cohort model predictions are always lower than corresponding ageperiod-cohort predictions, though the differences are small. The effects of recombining marital status are also small, though greater for 2001 than earlier years.

\section{Discussion}

Only when some attempt at forecasting is deemed crucial to the planning process-eg, fertility, mortality and population projections, or the likely progress of the HIV epidemic-is much effort expended on it. ${ }^{8-10}$ However, when we use forecasts to monitor mortality we can allow ourselves the luxury of being wrong and we can recalibrate our forecasts and predict in an iterative fashion as fresh observations are made. We can also confine our predictions to the immediate future, when extrapolations from past trends are likely to prove most accurate.

The basis of forcecasting is the assumption that prevailing trends will continue to operate in a predictable way. This assumption cannot be justified, so that confidence intervals based upon the forecasting model would be inappropriate. Hence, for cervical cancer mortality, because we believe that the introduction of a call and recall system should improve the screening programme through the 1990s and that post-AIDS sexual behaviour change is likely to have a favourable primary preventive effect, we present our results as an upper boundary which observed mortality should not cross if primary and secondary prevention is truly effective. If the limit is crossed, searching questions must be asked of the programme's performance. A recent forecast overestimated mortality observed and ours may also do so. Indeed the age-cohort model predictions for $1984-88$ at ages $30-39$ years were some $28 \%$ too high. We might well be observing the benefits

Table II Numbers of deaths age 20-69 years in 1991, 1996, 2001, predicted using age-period-cohort and age-cohort models for all women and reaggregated marital status (MS) total, based on the average predicted rates for the five year periods 1989-93, 1994-98, and 1999-2003 and the mid-year population projections for the three specific years

\begin{tabular}{|c|c|c|c|c|c|c|c|c|c|c|c|c|}
\hline \multirow{3}{*}{$\begin{array}{l}\text { Age } \\
\text { (years) }\end{array}$} & \multicolumn{6}{|c|}{ Age-period-cohort } & \multicolumn{6}{|c|}{ Age-cohort } \\
\hline & \multicolumn{3}{|c|}{ All women } & \multicolumn{3}{|c|}{ Reaggregated $M S$ total } & \multicolumn{3}{|c|}{ All women } & \multicolumn{3}{|c|}{ Reaggregated MS total } \\
\hline & 1991 & 1996 & 2001 & 1991 & 1996 & 2001 & 1991 & 1996 & 2001 & 1991 & 1996 & 2001 \\
\hline $\begin{array}{l}20-24 \\
25-29 \\
30-34 \\
35-39 \\
40-44 \\
45-49\end{array}$ & $\begin{array}{r}10 \\
37 \\
112 \\
158 \\
215 \\
165\end{array}$ & $\begin{array}{r}10 \\
52 \\
103 \\
227 \\
248 \\
277\end{array}$ & $\begin{array}{r}10 \\
54 \\
147 \\
210 \\
358 \\
323\end{array}$ & $\begin{array}{r}3 \\
51 \\
107 \\
158 \\
211 \\
161\end{array}$ & $\begin{array}{r}33 \\
63 \\
149 \\
218 \\
235 \\
270\end{array}$ & $\begin{array}{r}44 \\
69 \\
182 \\
311 \\
324 \\
296\end{array}$ & $\begin{array}{r}10 \\
35 \\
110 \\
155 \\
212 \\
165\end{array}$ & $\begin{array}{r}10 \\
52 \\
101 \\
224 \\
246 \\
275\end{array}$ & $\begin{array}{r}10 \\
52 \\
145 \\
206 \\
352 \\
319\end{array}$ & $\begin{array}{r}3 \\
49 \\
105 \\
153 \\
205 \\
159\end{array}$ & $\begin{array}{r}3 \\
61 \\
146 \\
210 \\
228 \\
264\end{array}$ & $\begin{array}{r}4 \\
66 \\
176 \\
301 \\
311 \\
287\end{array}$ \\
\hline All under 50 & 697 & 917 & 1102 & 691 & 938 & 1186 & 687 & 908 & 1084 & 674 & 912 & 1145 \\
\hline $\begin{array}{l}50-54 \\
55-59 \\
60-64 \\
65-69\end{array}$ & $\begin{array}{l}136 \\
123 \\
160 \\
228\end{array}$ & $\begin{array}{l}185 \\
131 \\
122 \\
146\end{array}$ & $\begin{array}{l}311 \\
178 \\
131 \\
112\end{array}$ & $\begin{array}{l}135 \\
125 \\
166 \\
229\end{array}$ & $\begin{array}{l}180 \\
130 \\
127 \\
156\end{array}$ & $\begin{array}{l}302 \\
173 \\
129 \\
119\end{array}$ & $\begin{array}{l}136 \\
122 \\
160 \\
229\end{array}$ & $\begin{array}{l}184 \\
130 \\
122 \\
147\end{array}$ & $\begin{array}{l}307 \\
176 \\
130 \\
112\end{array}$ & $\begin{array}{l}134 \\
124 \\
166 \\
231\end{array}$ & $\begin{array}{l}177 \\
129 \\
126 \\
156\end{array}$ & $\begin{array}{l}297 \\
171 \\
127 \\
119\end{array}$ \\
\hline All under 70 & 1344 & 1501 & 1834 & 1346 & 1531 & 1909 & 1334 & 1491 & 1809 & 1329 & 1500 & 1859 \\
\hline
\end{tabular}


of screening and changes in sexual behaviour already. However there may be potential for more accurate future estimations that take account of any consistent divergence between observation and expectation in this way over time.

Predictions based on the different trends in rates in subgroups of the population should prove more accurate than crude predictions for the whole population. We have no reason to believe that the prediction of trends in risk factors and hence future mortality will be more or less robust in the marital status subgroups than among all women combined. In effect therefore, we are standardising for differences in the mortality rates and the trends in these rates in these subgroups and for changes in population structure which will give these subgroups more or less social weight. By 2001 the numbers of single people are forecast to increase by $11 \%$ and divorcees by $64 \%{ }^{6}$ These marital status population projections too have limitations, as indeed do mid-year population estimates. ${ }^{811}$ However, although the direction of cohort effects on mortality has been similar for all generations (irrespective of marital status) born since the second world war, we believe the absolute size of these effects and their trajectory will mean mortality rates are sufficiently different to warrant embodying in the mortality forecast any error attributable to the extra difficulty of estimating or predicting populations in the marital status subgroups.

We suggest that the reaggregated marital status age-cohort model will best predict the future, since imposing estimated period values worsened the fit to reality for 1986 . It is perhaps of interest to note that average annual mortality both under 50 and under 70 years in the five year period 1984-88 predicted using the recombined marital status age-cohort model corresponded to within about one per cent of the figure observed in 1986 . The numbers of deaths given in table II are subject to uncertainty. Were the model from which they are derived correct then the standard errors of the numbers of deaths would correspond approximately to their square roots. It follows that proportionally greater stability is associated with the aggregates of age groups rather than the age groups singly. This was so in the 1984-88 estimates given in table I. It is also to be hoped that the period values which have been estimated here, all close to unity, will be followed in the future by a major downward trend. Prediction can first be compared with observation in 1991, shortly after the end of that year. We do not have long to wait and see.

We would like to thank Mrs Penny Callaghan of the Department of Public Health and Primary Care for typing the manuscript and Professor E G Knox for inspiration.

1 Murphy MFG, Campbell MJ, Goldblatt PO. Twenty years screening for cancer of the uterine cervix in Great Britain, screening for cancer of the uterine cervix in Great Britain,
1964-84: further evidence for its ineffectiveness. 9 Epidem 1964-84: further evidence for its ineffectiv

2 Parkin DM, Nguyen-Dinh $X$, Day $N$. The impact of screening on the incidence of cervical cancer in England and Wales. Br f Obstet Gynaecol 1985; 92: 150-7.

3 Day N. Screening for cancer of the cervix. I Epidemiol Community Health 1989; 43: 103-6.

4 Beral V, Booth $M$. Predictions of cervical cancer incidence and mortality in England and Wales. Lancet 1986; i: 495.

5 Murphy M, Vessey M, Villard L. Marital status and cervical cancer in young women. Lancet 1989; i: 1385-6.

6 Haskey J. Mid-1985 based population projections by marital status. Popul Trends 1988; 52: 30-2.

7 Osmond $\mathrm{C}$. Using age, period and cohort models to estimate future mortality rates. Int $f$ Epidemiol 1985 ; 14:124-9.

8 Daykin C. Projecting the population of the United Kingdom. Popul Trends 1986; 44: 28-33.

9 Alderson M, Ashwood F. Projection of mortality rates for the elderly. Popul Trends 1985; 42: 22-9.

10 Short term prediction of HIV infection and AIDS in England and Wales. Report of a working group. London: HMSO, 1988 .

11 Sparks J. Marital condition estimates 1971-85: a new series.
Popul Trends 1986; 45: 18-25. 